\title{
DESIGN AND IMPLEMENTATION OF A NOVEL ROBOT MANIPULATOR KIT FOR INDUSTRY 4.0 THROUGH EDUCATIONAL MECHATRONICS
}

\author{
Juan R. MIRANDA-FLORES ${ }^{1}$, Luis F. LUQUE-VEGA ${ }^{1}$, Emmanuel LÓPEZ-NERI ${ }^{1}$, Luis E. \\ GONZÁLEZ-JIMÉNEZ ${ }^{2}$ and Maarouf SAAD ${ }^{3}$ \\ ${ }^{1}$ Centro de Investigación, Innovación y Desarrollo Tecnológico CIIDETEC-UVM, Universidad \\ del Valle de México, 45601, Tlaquepaque, Jalisco, Mexico \\ ${ }^{2}$ Department of Electronics Systems and Computing ITESO AC, 45604, Tlaquepaque, Jalisco, \\ Mexico \\ ${ }^{3}$ Department of Electrical Engineering, École de Technologie Supérieure, Montreal, QC H3C \\ $1 \mathrm{~K} 3$, Canada
}

\begin{abstract}
The Educational Mechatronics is defined as the next stage of educational robotics, and it is integrated by the Educational Model of the University, resources and existing academic spaces, practical activities and mechatronic prototypes; it aims to develop the skills and abilities required by the jobs of the new industrial era, Industry 4.0. This work proposes the design and implementation of a robot manipulator kit for building the concept of kinematics in a natural way. This kit has several elements that can be mounted in different manners to have several robot configurations in order to teach the concepts of translation, rotation, homogeneous transformation matrix, forward and inverse kinematics, among other topics which are crucial to understand the core of the movements of a robot manipulator. The proposed robot manipulator kit is printed with $3 \mathrm{D}$ technology to make it accessible for more students. The active learning approach used in this work is focused on promoting the development of analytical thinking as a previous step forward of critical thinking competence, based on the three-step instructional approach : the concrete stage (robot manipulator kit), representational stage (coordinate frames) and the abstract stage (kinematic equations); in the framework of Education 4.0.
\end{abstract}

Keywords: Educational mechatronics, robotics, Industry 4.0.

\section{INTRODUCTION}

The next era of the industrial revolution is a reality and many companies are integrating the concepts of industry 4.0 into their processes. Industry 4.0 proposes the digitalization of companies using artificial intelligence (AI) and the internet of things (IoT). The incorporation of new technologies within the industrial environment has been changing business models as we knew them. In recent years, the interest in identifying the different scenarios that Industry 4.0 brings has grown due to the new challenges that appear in the horizon. Actually, there are four key components of Industry 4.0: Cyber- Physical Systems, Internet of Things, Internet of Services, and Smart Factory [1].

Educational mechatronics is devoted to close the gap between what Industry 4.0 is requiring and what Universities are offering, in terms of human resources [2]. But before, explaining what Educational mechatronics is, first we must take a brief on Educational Robotics. Currently, educational robotics is used as a pedagogical tool for the soft /hard skills development, using didactic models and constructivist pedagogical methods oriented to the construction of variables wiring and structures, allowing the students experiment and validate their own designs [3], [4], [5]. However, the principal validated impact of this proposals is the engagement and interest in educational robotics activities, and the skill development to wire, using structures, but doesn't develop in the student the mechatronics basic concepts, so the student cannot develop more complex solutions as is required today by the uncertainty and exponential growth of technology and problems in industry 4.0 era. Although has been developed some proposals focused on the development in the student's industry 4.0 concepts using constructivist method applying project-based and team-based learning [6], [7], [8], the student mainly develops the 
ability to challenges around specific configurations of robot manipulators or robotic production lines, and doesn't focus on mechatronics concepts as by example instead of developing the workspace of a robot manipulator, the learning process is focused in learning the specific structure of the robot. However, educational robotics is limited to the use of higher level of abstraction concepts than mechatronic concepts, so that proposal implies having to leave the concept of educational robotics and return to that of mechatronic basic concepts, a process that implies a lower layer in the definition of the concept of educational robotics. In addition, the learning process is conceived as a mechanical consequence of their assimilation, so that students learn solutions for such mechanized patterns, so when problems arise that do not correspond to the pattern learned, frustration occurs in the student. Therefore, a strategy is required to ensure the development of student learning from the mechatronic concepts focused on the construction of knowledge and skills required in industry 4.0 that involves the organization of knowledge in a structured way.

This work proposes the design and implementation of a robot manipulator kit following the three-step instructional approach; the concrete stage (robot manipulator kit), representational stage (coordinate frames) and the abstract stage (kinematic equations) that is commonly used in mathematics teaching. The authors are introducing the new concept of Educational Mechatronics as the next level of Educational Robotics. It is interesting to consider whether this new educational methodology really represents a good alternative to develop the abilities, skills and attitudes of the students who will be the main actors of the new jobs required in Industry 4.0 and how well it adapts in the framework of Education 4.0. The following sections describe the Educational Mechatronics Conceptual Framework (EMCF), the design and implementation of the Robot Manipulator Kit for Industry 4.0, the instructional design for this kit and some conclusions closes the paper.

\section{EDUCATIONAL MECHATRONICS CONCEPTUAL FRAMEWORK (EMCF)}

The EMCF aims to guide to teachers on the design, implementation and evaluation of pedagogical activities to develop the mechatronic thinking in the students, the latter understood as the capacity for the design and implementation of production systems [9] under the principle of interdisciplinary collaboration and the concept of multidisciplinary provision of knowledge [10]; in a flexible way [11], [12], considering the high-level intelligence hierarchy as the backbone of mechatronic system [13], [14]. Educational Mechatronics is intended to take the student to understand abstract concepts on which the applications, we call mechatronics, are built and thus be able to face the speed of growth and exponential change of industry 4.0, responding to the mega trends of the manufacturing industry, advanced manufacturing processes, focusing on the development, application or integration of a set of enablers and technologies in order to generate impact [15]. The EMCF is structured into three reference perspectives: process, application and artefact [16] as shown in Figure 1. The first perspective is oriented to mechatronics basic concepts as process. The second perspective comprehends all the applications (sub-disciplines) from the mechatronic basic concepts, and finally the artefact, oriented to get some artefacts related to the process and applications construction.

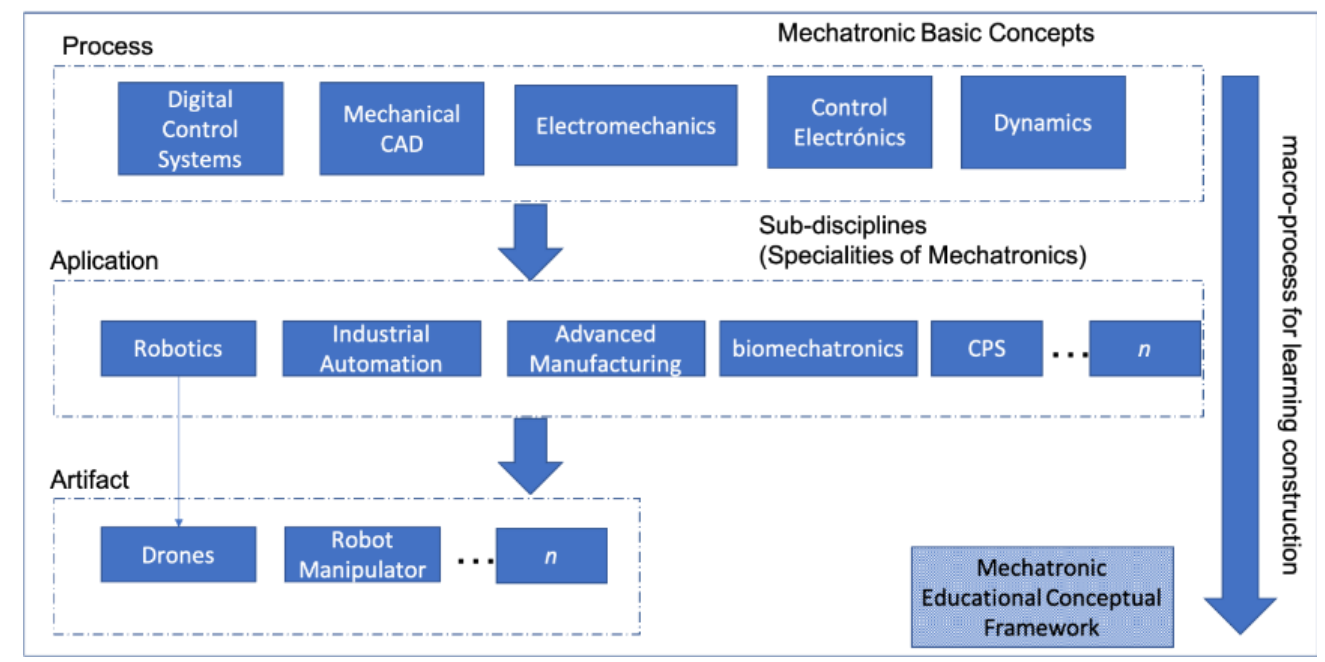

Figure 1. The mechatronic educational framework and disciplines. 
The EMCF Learning Construction Methodology (EMCF-LCM) is a macro-process based on a structured teaching methodology similar to [15], [16], and it is show in Error! Reference source not found.Error! Reference source not found. This EMCF-LCM is composed of three learning levels: the concrete, the graphic and the abstract levels.

* The concrete level: has to do with the process of manipulation and experience with real objects, that is, a learning focused on the student's experience with situations of their reality or specific objects [17], [18].

* The graphic level: are represented the elements of reality (concrete level) with graphics or symbolic elements, enabling students to integrate this knowledge as a skill [18].

* The abstract level: has to do with a totally focused learning outside your reality, and the level of major abstraction.

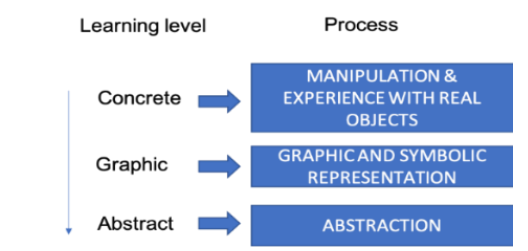

Figure 2. Educational Mechatronics Conceptual Framework macro-process levels and processes involved in the construction of learning.

\section{ROBOT MANIPULATOR KIT FOR INDUSTRY 4.0}

The first proposed mechatronic prototype is the robot manipulator which is made up of various components that can be assembled depending on the topic you want such as: translation, rotation, homogeneous transformation matrix, forward and inverse kinematics, or other topic which are crucial to understand the core of the movements of a robot manipulator.

\subsection{Design and implementation of the robot manipulator}

A proper modelling methodology defines the best order to create a design in SolidWorks so that we can get the best efficiency from our model for performance, modelling changes and revisions and all the other items that a file will need to go thru during it life cycle. Then, we consider several different items before we start to create a model [17]:

- Manufacturing: Defines how the part is going to be manufactured, then the design considers only the use of a $3 \mathrm{D}$ printing and some aluminium parts.

- Features: Considers two scenarios: a traditional room and a motion capture (MoCap) system.

- Assemblies and Drawings: Defines how your parts are going to interact with the complete assembly. Since the proposed robot manipulator kit is intended to be accessible for more students it is fabricating using 3D printing technology with polylactic acid (PLA) plastic, and with some parts of aluminium. Once that 3D models of each piece are design, the 3D printing process can start for most of the components of the robot manipulator. To be specific, the components $1,3,4,5,6,8,12,13,14,15$ and 23 are fully made in PLA plastic using a normal 3D printing process. Besides, the aluminium is used specifically in the base link, component 2 , and the graduate link to hold the weight and stress that the complete model could generate. Finally, component 7 (MoCap marker) is a special piece that is covered in a reflective the light material and it is intended for using in the motion capture system. The results that lead following the modelling methodology are depicted in Figure 3, containing the exploded view with all its components, two different configurations, that are constructed in a sequence in order to build the knowledge of robot kinematics. 

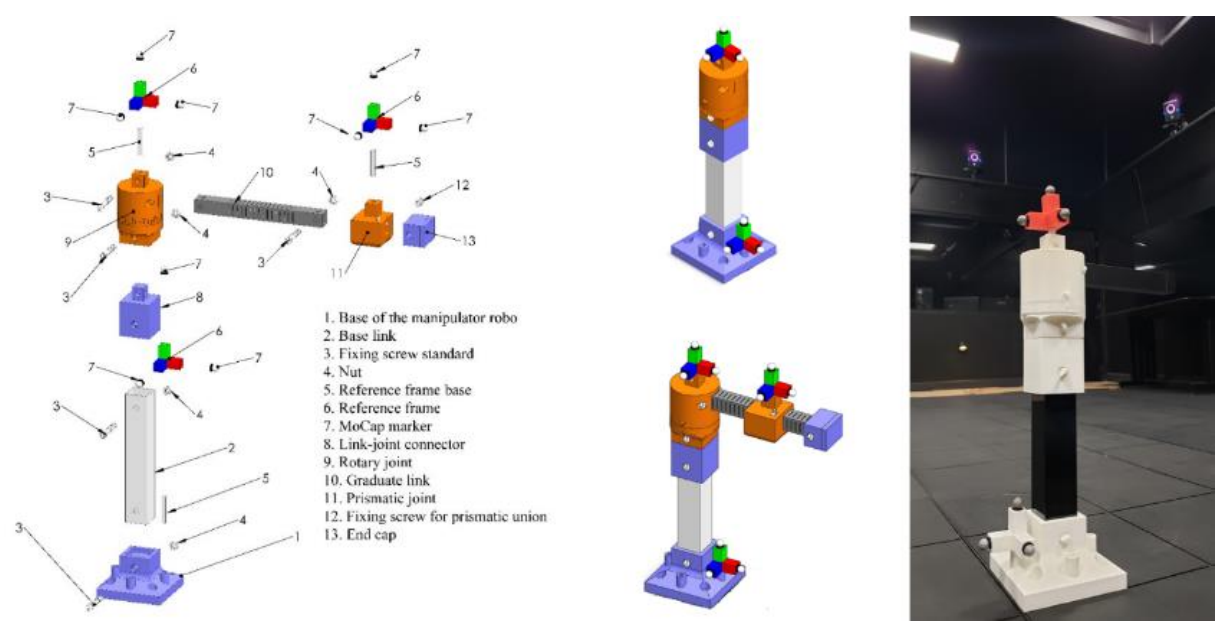

Figure 3. Exploded view of the Robot Manipulator containing all its components, two different configurations of the Robot Manipulator Kit and the implemented robot manipulator prototype

\section{INSTRUCTIONAL DESIGN FOR MECHATRONIC CONCEPT: WORKSPACE OF A ROBOT MANIPULATOR}

The robot manipulator kit is useful when dealing with the concepts of translation, rotation, homogeneous transformation matrix, forward and inverse kinematics, among other topics. This work considers the teaching case for which the instructional design is devoted to construct the mechatronic concept of workspace of a robot manipulator under the EMCF, involving the perspective entities: Kinematics (process) + Robotics (Application) + Robot Manipulator (Artefact). Then, the pedagogical activities for the three levels with the selected perspective are developed. The mechatronic concept is:

"The reachable workspace is the entire set of points reachable by the manipulator"

It is worthwhile to mention that workspace of a manipulator is the total volume swept out by the endeffector as the manipulator executes all possible motions. The workspace is constrained by the geometry of the manipulator as well as mechanical constraints on the joints. Now, we derive the process for applying the EMCF-LMC (see Error! Reference source not found.):

- Concrete learning level: In this level must be designed activities oriented to perceptuo-motor characteristics. We limit the range of robot manipulator movement from $0^{\circ}$ to $90^{\circ}$ for the rotary joint and the prismatic joint fixed to $230 \mathrm{~mm}$. The home position for robot manipulator is $0^{\circ}$ and 230 mm.

- Graphic learning level: In this level must be designed activities oriented to graphic (symbolic) representation of mechatronic concepts taking as reference the previously developed concepts at the concrete learning level, this will allow to gradually make the transition from concrete to abstract. The graphic level is carried out using the Motion Capture (MOCAP) System which consist of eight cameras Vantage V16, a Lock Sync Box, a power over ethernet (PoE) switch and the PC with Vicon Tracker software. Each camera contains a thermal sensor to detects changes in temperature that could affect the system status. The power and connectivity are through PoE+ protocol by CISCO. The Lock Sync Box, connect, integrate and synchronize the cameras trough PoE switch with software. Some features of the Vicon Tracker software are: Track multiple objects, single camera tracking and real-time system modelling with Simulink.

- Abstract learning level: In this level must be designed activities oriented to gradually transit from the symbolic concepts to an abstract representation that includes mathematical equations.

Table 1. EMCF-LMC Process.

\begin{tabular}{|c|c|c|}
\hline Concrete level & Graphic level & Abstract level \\
\hline $\begin{array}{l}\text { 1. Start with the robot manipulator in its } \\
\text { home position }\end{array}$ & 1. Turn on the MoCap System & \multirow{3}{*}{$\begin{array}{l}\text { 1. Considering the set of points generated } \\
\text { in graph paper, if they relate to a line, it } \\
\text { describes what in mathematics is known as } \\
\text { a quarter of a circle (see Figure 5). }\end{array}$} \\
\hline $\begin{array}{l}\text { 2. Place a graph paper under the } \\
\text { manipulator robot. }\end{array}$ & $\begin{array}{l}\text { 2. Place the robot manipulator base matching } \\
\text { the origin of the MoCap and place robot } \\
\text { manipulator in its home position. }\end{array}$ & \\
\hline $\begin{array}{l}\text { 3. Place the switch in the ON position to } \\
\text { turn on the red laser that represents the } \\
\text { end-effector of the robot manipulator. }\end{array}$ & $\begin{array}{l}\text { 3. Start the display of the position and } \\
\text { orientation for the } 3 \text { references systems: base, } \\
\text { rotary joint and prismatic joint (represent the } \\
\text { end-effector of the robot manipulator). }\end{array}$ & \\
\hline
\end{tabular}




\begin{tabular}{|c|c|c|}
\hline $\begin{array}{l}\text { 4. Mark with a marker the point where } \\
\text { the laser is reflected on the paper. }\end{array}$ & 4. Start recording the data & \\
\hline $\begin{array}{l}\text { 5. Turn the arm only one position } \\
\text { counterclockwise (see Figure 4). }\end{array}$ & $\begin{array}{l}\text { 5. After } 12 \text { seconds, turning the arm } \\
\text { counterclockwise and continuously from } 0^{\circ} \text { to } \\
\text { reach } 90^{\circ} \text { and wait } 5 \text { seconds. Finally turn the } \\
\text { arm again to return to } 0^{\circ} \text { and stop. }\end{array}$ & Norksp \\
\hline $\begin{array}{c}\text { Figure 4. Movement of the robot } \\
\text { manipulator }\end{array}$ & & $\begin{array}{l}\text { Figure 5. Workspace of the robot manipulator } \\
\text { in a top view. }\end{array}$ \\
\hline $\begin{array}{l}\text { 6. Repeat step } 3 \text { and } 4 \text { until you reach } 9 \\
\text { positions. }\end{array}$ & 6. Stop & \multirow{4}{*}{$\begin{array}{l}\text { 2. Then, the equations describing the } \\
\text { parametric form of a circle (connected line } \\
\text { of points from subsection } 4.2) \text { is } \\
\text { where } \quad F(\theta)=(x(\theta), y(\theta)) \\
\qquad x(\theta)=r \cos (\theta)+h \\
\qquad y(\theta)=r \sin (\theta)+k \\
\text { with } \theta \text { being the angle of rotation }\left(0^{\circ}<\right. \\
\left.\theta<90^{\circ}\right) \text { (Figure .c), } r \text { the radius of the } \\
\text { graduate link of the robot and }(h, k) \text { is the } \\
\text { center of the circle (base of the robot). } \\
\text { Instruction remark: the } x \text { and } y \\
\text { coordinates define the set of points } F(\theta) \\
\text { reachable by the manipulator, also called } \\
\text { workspace. }\end{array}$} \\
\hline $\begin{array}{l}\text { 7. Make a table with two columns: first } \\
\text { column contains the } x \text {-coordinate and the } \\
\text { second column the } y \text {-coordinate of the } \\
\text { ith-point. }\end{array}$ & $\begin{array}{l}\text { 7. Obtain the Excel file containing the recorded } \\
\text { date. }\end{array}$ & \\
\hline \multirow{2}{*}{$\begin{array}{l}\text { 8. Add to the table each of the points } \\
\text { marked on the paper. (Instruction } \\
\text { remark: this table will contain the set of } \\
\text { points reachable by the manipulator, also } \\
\text { called workspace.) }\end{array}$} & $\begin{array}{l}\text { 8. Plot the orientation and position of the end- } \\
\text { effector reference system. }\end{array}$ & \\
\hline & $\begin{array}{l}\text { 9. Draw four vertical lines in the plot for } \\
t_{1} \rightarrow \text { start counterclockwise movement, } t_{2} \rightarrow \text { stop } \\
\text { counterclockwise movement, } t_{3} \rightarrow \text { start } \\
\text { clockwise movement and } t_{4} \rightarrow \text { stop clockwise } \\
\text { movement. } \\
\text { Instruction remark: the } x \text { and } y \text { charts define } \\
\text { the set of points reachable by the manipulator, } \\
\text { also called workspace. }\end{array}$ & \\
\hline
\end{tabular}

Figure 6 shows an example of the resultant plot containing the absolute position and angular position of the end effector is shown. It can be noted that end-effector reference system of the Robot Manipulator contains the reachable points for the manipulator (workspace) defined by the shaded area between $t_{1} \mathrm{y}$ $t_{2}$ that corresponds to a counter clockwise and continuously turning from $0^{\circ}$ to $90^{\circ}$ (see Figure $6 . \mathrm{d}$ and Figure 6.e). Moreover, the shaded area between $t_{3}$ y $t_{4}$ corresponds to the reachable points for the manipulator (workspace) in a clockwise and continuously turning from $90^{\circ}$ to $0^{\circ}$ (see Figure $6 . \mathrm{d}$ and Figure 6.e).
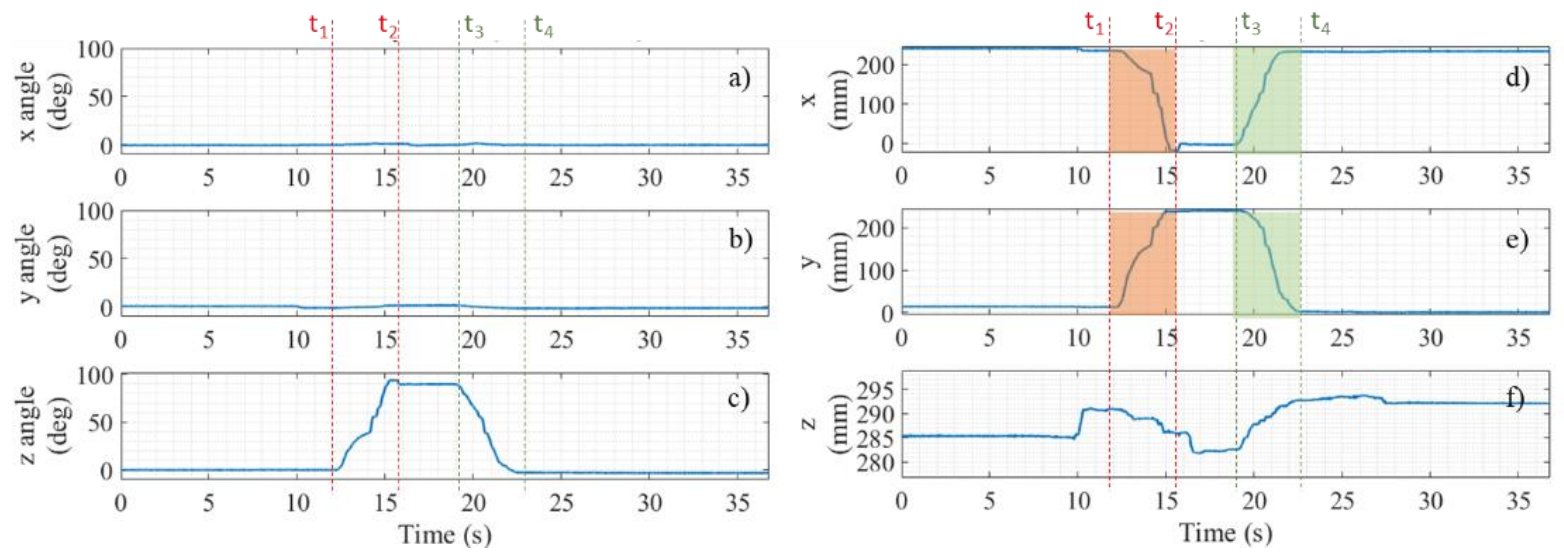

Figure 6. End-effector reference system of the Robot Manipulator

\section{CONCLUSIONS}

In order to face the challenges of Industry 4.0 it is crucial to have a development framework such as EMCF that allows visualize and interact with elements or concepts in a three-level process, and not to do so from a more reduce and specific concept such as educational robotics. In fact, educational robotics remains as an artefact of applying the macro-process of EMCF, this allows to guide learning to comply with the characteristics of mechatronic thinking: flexibility, attend to processes, applications and artifacts, in a holistic way. The didactic models used in robotic educational mechatronics, are focused mainly to develop students' skills to wire, using predefined structures. Other didactic models are focused on the use of specific robotic configurations previously stablished. The proposal EMCF provides a framework to develop multiple didactic cases to develop any mechatronic concept based on constructivism approach. In particular, the presented instructional design for Robot Manipulator is intended to better prepare students on kinematics to acquire the necessary knowledge for be prepare when they require to use and program a real robot manipulator in some application in Industry 4.0. By 
following this manual, the student will obtain the knowledge, skills and attitudes to meet the new demands of the companies through an educational playful. We consider it essential to disseminate educational mechatronics to help Mexico in its transformation to become a relevant actor in the fourth industrial revolution.

\section{ACKNOWLEDGMENTS}

This work is funding by Laureate Education Inc. through the 2018 David A. Wilson Award for Excellence in Teaching and Learning. Besides, we would like to thank the Mexican National Council of Science and Technology CONACYT for the scholarship 227601 and the State Council of Science and Technology COECyTJAL for supporting the Quebec-Jalisco work team 2019-2021: Mechatronics 4.0. Moreover, we thank to Dr. Carlos A. Arellano-Muro, Dr. Jorge E. Ruíz-Duarte, Dr. Neín FarreaVázquez, Dra. Miriam A. Carlos-Mancilla, Ing. David Palafox-Byron, Ing. Nadia C. Hoeflich-Mercado, Ing. Carlos Juárez-Díaz, who have been collaborating in the development of this project.

\section{REFERENCES}

[1] Hermann, M., Pentek, T. and Otto, B. "Design Principles for Industrie 4.0 Scenarios: A Literature Review," Working Paper No. 01/2015, pp. Technische Universität Dortmund, January 2015., 2015.

[2] Luque-Vega, L.F., Lopez-Neri, E., Santoyo, A., Ruiz-Duarte, J.E., and Farrera-Vázquez, N., "Educational Methodology Based on Active Learning for Mechatronics Engineering Students: Towards Educational Mechatronics," Computación y Sistemas, vol. 23, no. 2, p. 325-333, 2019.

[3] Kelemenová, T., Frankovský, P., Virgala, I., Miková, L., Kelemen, M. and Dominik, L., "Educational Models for Mechatronic Courses," Acta Mechatronica, vol. 1, no. 4, pp. 1-6, 2016.

[4] Lammer, L., Lepuschitz, W., Kynigos, C., Giuliano, A. and Girvan, C. "ER4STEM Educational Robotics for Science, Technology, Engineering and Mathematics, " in Robotics in Education, Switzerland, Springer, Cham, 2016, pp. 95-101.

[5] Atmatzidou, S. and Demetriadis, S. "Advancing students' computational thinking skills through educational robotics: A study on age and gender relevant differences, " Elsevier, Robotics and Autonomous Systems, vol. 75, no. Part B, p. 661-670, 2016.

[6] Richert, A., Shehadeh, M., Plumanns, L., Groß, K., Schuster, K. and Jeschke, S. "Educating engineers for industry 4.0: Virtual worlds and human-robot-teams: Empirical studies towards a new educational age, " in 2016 IEEE Global Engineering Education Conference (EDUCON), Abu Dhabi, United Arab Emirates, 2016.

[7] Tosello, E., Castaman, N. and Menegatti, E. "Using robotics to train students for Industry 4.0," in 12th IFAC Symposium on Advances in Control Education ACE 2019, Philadelphia, PA, USA, 2019.

[8] Verner, I., Cuperman, D., Romm, T., Reitman, M., Chong, S.K. and Gong, Z. "Intelligent Robotics in High School: An Educational Paradigm for the Industry 4.0 Era," in The Challenges of the Digital Transformation in Education, Springer International Publishing, 2020, pp. 824-832.

[9] Lüder, L., Foehr, M., Köhlein, A. and Böhm, B. "Application of engineering processes analysis to evaluate benefits of mechatronic engineering, " in Proceedings of 2012 IEEE 17th International Conference on Emerging Technologies \& Factory Automation (ETFA 2012), Krakow, Poland, 2012.

[10] Ziyi, Z., Zhiyong, M., Zhiqin, Y. and Kailu, D. "Combine Different Knowledge, Train Students Mechatronic Thinking, " International Journal of Education and Management Engineering., vol. 2, pp. 14-19, 2013.

[11] Dache, L. and Pop, S.F. "Education, Knowledge and Innovation from a Mechatronics Perspective," Procedia - Social and Behavioural Sciences, pp. 205-209, 2015.

[12] Steinbuch, M. "Mechatronics Disrupted," in Mechatronics Futures, Switzerland, Springer International Publishing, 2016, pp. 17-24.

[13] Mazid, A.M. "Philosophy of mechatronics course development," in 2002 IEEE International Conference on Industrial Technology, 2002. IEEE ICIT '02, Bangkok, Thailand, Thailand, 2002.

[14] Tomizuka, M. "Mechatronics: from the 20 th to $21^{\text {st }}$ Century," Control Engineering Practice, vol. 10, pp. 877-886, 2002.

[15] Santaliana, D., Calloni, D., Laterza, V. and Zanelli, R. "Report on assessment skills and needs in the mechatronics and metallurgical sectors industries in the 5 Countries," September 2019. 
[Online]. Available: http://www.memevet.eu/wp-content/uploads/2019/09/REPORT-ONSKILLS-AND-NEEDS_Final_V5_Revised-by-Partnership_13_09_19.pdf. [Accessed February 2020].

[16] Drescher, B. and. Reinhart, G. "Reference Model for the Description of Digital Engineering Tools based on Mechatronic Principles and Concepts," Advanced Materials Research, vol. 1018, pp. 547-554, 2014.

[17] Altergott, J. "SolidWorks Modelling Methodology: Before You Start Your Design," The SolidWorks Blog, 06 2013. [Online]. Available: https://blogs.solidworks.com/solidworksblog/2013/06/solidworks-modeling-methodology-part1.html. [Accessed February 2020].

[18] Spong, M.W., Hutchinson, S. and Vidyasagar, M. Robot Modelling and Control, New York / Chichester / Weinheim / Brisbane / Singapore / Toronto: John Wiley \& Sons, Inc., 2006. 